\title{
Catalytic behavior of alkali-treated Pt/HMOR in $n$-hexane hydroisomerization
}

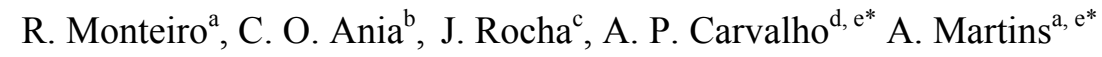

${ }^{a}$ Instituto Superior de Engenharia de Lisboa, Área Departamental de Engenharia Química, R. Conselheiro Emídio Navarro, 1959-007 Lisboa, Portugal

${ }^{b}$ Dpt. Chemical Processes for Energy and Environment, Instituto Nacional del Carbón (INCAR, CSIC), Apdo. 73, 33011 Oviedo, Spain

${ }^{c}$ Universidade de Aveiro, Departmento de Química, CICECO, 3810-193 Aveiro, Portugal

${ }^{d}$ Departamento de Química e Bioquímica, Universidade de Lisboa, Faculdade de Ciências, Campo Grande C8, 1749-016 Lisboa, Portugal

${ }^{e}$ Centro de Química e Bioquímica, Faculdade de Ciências da Universidade de Lisboa, Campo Grande C8, 1749-016, Lisboa, Portugal.

Corresponding Authors: A. Martins, Área Departamental de Engenharia Química, Instituto Superior de Engenharia de Lisboa, R. Conselheiro Emídio Navarro, 1959-007 Lisboa, Portugal; Tel: +351 218317000; Fax: +351 218317001; E-mail address: amartins@deq.isel.ipl.pt; A. P. Carvalho, Faculdade de Ciências da Universidade de Lisboa, Campo Grande C8, 1749-016 Lisboa, Portugal; Tel.: +351 217500897; Fax: +351 217500088; E-mail address: ana.carvalho@fc.ul.pt.

\begin{abstract}
Bifunctional Pt-HMOR catalysts were prepared by incipient wetness impregnation of various desilicated MOR obtained by alkaline treatment using $\mathrm{NaOH}$ concentrations ranging from 0.1 to 0.5 M. The zeolite structural changes upon modification were investigated by several techniques including powder X-ray diffraction, ${ }^{27} \mathrm{Al}$ and ${ }^{29} \mathrm{Si}$ MAS-NMR spectroscopy, $\mathrm{N}_{2}$ adsorption, pyridine adsorption followed by infrared spectroscopy and the catalytic model reaction of $m$ -
\end{abstract}


xylene transformation. For low alkaline concentration the zeolite acidity is preserved, along with a slight increase of the volume correspondent to the larger micropores due to the removal of extra-framework debris already existent at the parent zeolite At higher $\mathrm{NaOH}$ concentrations there is a significant loss of crystalinity and acidity as well as the formation of mesoporosity. The characterization of the metal function show similar patterns for Pt-HMOR and Pt-M/0.1 samples, with Pt particles located mainly inside the inner porosity. In contrast, large Pt particles become visible at the intercrystalline mesoporosity of MOR crystals developed during the desilication treatments at severe alkaline conditions. The catalytic results obtained for $n$-hexane hydroisomerization showed an improved selectivity for dibranched over monobranched isomers for Pt-M/0.1 sample, likely due to the preservation of the support acidity and the slight enlargement of the micropores. This work is a new example in which the mesoporous development does not improve the catalytic efficiency of the zeolites, whereas mild alkaline desilication might be considered as an effective solution to produce customized catalysts with enhanced performance for a given application.

Keywords: MOR; Desilication; Bi-functional catalysts; Acidity; Platinum; $n$-Hexane hydroisomerization 


\section{Introduction}

Current gasoline specifications being implemented worldwide impose strong restrictions on limiting the amounts of aromatic and olefinic compounds [1], whereas iso-alkanes, especially multibranched alkanes are highly desired in gasoline blend stocks due to their ability to increase the octane number. As a result, hydroisomerization of linear $\left(\mathrm{C}_{5}-\mathrm{C}_{6}\right)$ paraffins into high octane number branched isomer has gained importance nowadays. This catalytic reaction is usually carried out over bi-functional catalysts comprised of a metal function (typically nobel metals as Pt or Pd) dispersed on an acid supports. Among them, metal loaded zeolites, especially monodimensional mordenite (MOR) or mazzite (MAZ), are widely used due to their strong acidity, the high metal dispersion on their large open porous network comprised of varied pore shapes, and availability of different structures and morphologies [2]. Indeed, the application of bi-functional zeolite-based catalysts in upgrading the octane number of light naphtha through hydroisomerization reactions has a commercial application [1]. Following the bi-functional mechanism $n$-alkenes resulting from dehydrogenation of $n$-alkanes on the metallic sites undergo skeletal isomerization on the acid sites of the support; the resulting intermediate is then hydrogenated on another metallic site or, alternatively, undergoes a second isomerization or even cracking [3]. The balance between the number of acid and metallic sites plays a determinant role on the activity and product selectivity of this reaction [4], in addition to other parameters like pore geometry and accessibility [5]. The effect of $\mathrm{Si} / \mathrm{Al}$ ratio of the support is also important and, for instance, it has been reported that dealumination of a MOR zeolite leads to an increase of Pt/MOR catalysts activity until an optimum Si/Al ratio is reached [6]. Such optimum $\mathrm{Si} / \mathrm{Al}$ value was interpreted as the result of two antagonistic effects: the removal of obstructing species during the dealumination process (thus the enlargement of the pores), and the reduction of the number of acid sites. Nevertheless these materials suffer from the drawback of constrained space available for the formation of bulkier product molecules inside the pores, which can be more accentuated after metal deposition due to possible formation of metal clusters inside the pores. On the other hand, some authors claim that the hydroisomerization reaction occurs mostly at the zeolite pore mouths [7], and therefore a significant number of 
internal active sites are unused. One of the strategies to overcome this drawback is the generation of mesoporosity in addition to the intrinsic microprosity of the zeolites. This can be obtained through, among other strategies, by alkaline treatments which have been successfully applied to a great number of zeolite structures, including MOR [8-12]. In these post-synthesis treatments, the controlled extraction of Si from the zeolite framework can be reached without significant impact on the zeolite crystallinity or active sites density, under a careful control of the experimental conditions (i.e., temperature, base concentration, duration of the treatment) $[8,11,13]$. Some studies have reported the benefits on the catalytic performance of desilication over dealumination treatments, since the results obtained with desilicated samples show a slower deactivation rate $[15,16]$, increasing the catalytic activity $[17,18]$ or improving the selectivity into more valuable products $[14,19]$. However, the use of desilicated zeolites as bifunctional catalysts, particularly in short chain n-alkane transformation, has been scarcely explored. For instance, Chao et al. [20] explored the potentialities of mesoporous ZSM-5 obtained by alkaline post-treatments and observed changes in the product selectivity and adsorption properties. Song et al. [21] studied the effect of the desilication treatment on ZSM-5, and observed an enhancement in the yield of dibranched isomers due to the formation of mesopores. Modhera et al. [22] also studied the catalytic performance of Pt impregnated desilicated ZSM-5 and Beta zeolites for $n$-hexane hydroisomerization, reporting modifications in Pt location that were correlated to a reduced catalyst deactivation by sintering.

Despite Pt-loaded MOR is currently used in industry for short chain $n$-alkane hydroisomerization reaction, to the best of our knowledge no studies have been reported on the catalytic performance of desilicated MOR. Thus, the purpose of this work was to explore the behavior of alkaline treated MOR zeolite as acid support in $n$-hexane hydroisomerization.

\section{Experimental}

\subsection{Parent material}

As a starting material a mordenite structure $\left(\mathrm{NH}_{4} \mathrm{MOR}\right)$ supplied by Zeolyst (CBV21 A, lot. 2200-83) was used. According with the technical report, the sample has a $\mathrm{SiO}_{2} / \mathrm{Al}_{2} \mathrm{O}_{3}=20$ and a 
$\mathrm{Na}_{2} \mathrm{O}$ weight $\%$ of 0.008 . The parent sample was converted to the protonic form (HMOR) by calcination under dry air $\left(6 \mathrm{dm}^{3} \mathrm{~h}^{-1} \mathrm{~g}^{-1}\right)$ at $500^{\circ} \mathrm{C}$ for $3 \mathrm{~h}$.

\subsection{Alkaline treatment of HMOR zeolite}

The alkaline treatments were performed using $\mathrm{NaOH}$ as desilicating agent and following the experimental procedure described elsewhere $[11,23]$. In brief, HMOR was stirred during 2 hours at $85{ }^{\circ} \mathrm{C}$ (conventional heating plate) in $\mathrm{NaOH}$ (Merck, p.a) solution (ratio $330 \mathrm{mg} / 10$ $\mathrm{cm}^{3}$ ) using a concentration range 0.1-1M. Subsequently, the suspension was filtered, washed thoroughly up to $\mathrm{pH} 7$ and dried overnight at $90{ }^{\circ} \mathrm{C}$. The alkaline treated solids were converted into the correspondent protonic form by three consecutive exchanges in $1 \mathrm{M} \mathrm{NH}_{4} \mathrm{NO}_{3}$ (Merck, p.a.) at $80^{\circ} \mathrm{C}$ during $3 \mathrm{~h}$ each, using a ratio $50 \mathrm{~cm}^{3}$ per gram of zeolite. The solids were carefully washed again up to final $\mathrm{pH}$ of 7 , and then calcined under air flow $\left(6 \mathrm{dm}^{3} \mathrm{~h}^{-1} \mathrm{~g}^{-1}\right)$ at $500^{\circ} \mathrm{C}$ for 3 h. The treated samples will be designated as $M / x$, being $x$ the concentration of the $\mathrm{NaOH}$ solution (M) used in the desilication step.

\subsection{Preparation of bi-functional catalysts}

Platinum was introduced on the pristine and desilicated zeolites by incipient wetness impregnation, using an aqueous solution of $\mathrm{Pt}\left(\mathrm{NH}_{3}\right)_{4} \mathrm{Cl}_{2} \cdot \mathrm{xH}_{2} \mathrm{O}$ (Aldrich, 98\%) of adequate concentration so as to obtain a $1 \mathrm{wt} . \% \mathrm{Pt}$ content. The solids were dried overnight at $80{ }^{\circ} \mathrm{C}$ and calcined at $500{ }^{\circ} \mathrm{C}$ for $2 \mathrm{~h}$ under $\mathrm{N}_{2}$ flow of $12 \mathrm{dm}^{3} \mathrm{~h}^{-1} \mathrm{~g}^{-1}$ to allow the decomposition of the $\mathrm{Pt}$ precursor. The bi-functional catalysts will be designated as $\mathrm{Pt}-\mathrm{M} / \mathrm{x}$, being $\mathrm{x}$ as indicated above.

\subsection{Physicochemical characterization}

The structural characterization of the pristine and modified zeolites was carried out by powder X-ray diffraction (XRD), measured in a Philips PX-1730 diffractometer with automatic data acquisition (APD Philips (v3.6B) software) and using $\mathrm{CuK} \alpha$ radiation as incident beam. Diffractograms were acquired by continuous scanning from $5^{\circ}$ to $40^{\circ} 2 \theta$, with a step size of $0.02^{\circ} 2 \theta$ and a time per step of $20 \mathrm{~s}$. Integration of the peaks area was made using "Peak Fit" 
software. ${ }^{27} \mathrm{Al}$ and ${ }^{29} \mathrm{Si}$ MAS NMR spectra were recorded on Bruker Avance III 400 NMR spectrometer $\left(\mathrm{B}_{0}=9.4 \mathrm{~T}\right)$ at, respectively, 104.2 and $79.5 \mathrm{MHz}$, using $9^{\circ}$ and $45^{\circ} \mathrm{rf}$ pulses, $1 \mathrm{~s}$ and $60 \mathrm{~s}$ recycle delays and MAS rates of 14 and $5 \mathrm{kHz}$. Chemical shifts are quoted in ppm from, respectively, $\mathrm{Al}\left(\mathrm{H}_{2} \mathrm{O}\right)_{6}{ }^{3+}$ and tetramethylsilane (TMS). The global Si/Al was calculated from the $\mathrm{Al}$ and $\mathrm{Si}$ contents determined from inductively coupled plasma atomic emission spectrometry (ICP-AES Horiba Jobin-Yvon mod. Ultima) and atomic absorption spectrometry (AAS), respectively. Analyses were performed at "Laboratório de Análises", IST, Lisboa, Portugal.

Pt dispersion was evaluated by Transmission Electron Microscopy (TEM, Hitachi $\mathrm{H}-8100$ apparatus operating at $200 \mathrm{kV}$ ) and $\mathrm{H}_{2}$ pulse chemisorption at $25{ }^{\circ} \mathrm{C}$ (Micromeritics ASAP 2900 unit equipped with a TCD detector). Prior to pulse chemisorption experiments, all samples were reduced under $\mathrm{H}_{2} / \mathrm{Ar}$ flow $\left(50 \mathrm{~cm}^{3} \mathrm{~min}^{-1}\right)$ for $1 \mathrm{~h}$ at $350{ }^{\circ} \mathrm{C}$. For each pulse chemisorption analysis, about 40-50 mg of sample were treated with an Ar flow of $50 \mathrm{~cm}^{3} \mathrm{~min}^{-1}$ and pulses of $0.05 \mathrm{~cm}^{3}\left(10 \% \mathrm{H}_{2}\right.$ in Ar) until saturation of the catalysts. To calculate metal dispersion, adsorption stoichiometry of $\mathrm{H} / \mathrm{Pt}=1[24]$ was assumed.

The textural characterization of the solids was made by $\mathrm{N}_{2}$ adsorption isotherms measured in an automatic apparatus Micromeritics ASAP 2010. Before the isotherms acquisition the samples $(\approx 50 \mathrm{mg})$ were outgassed for $2 \mathrm{~h}$ at $300^{\circ} \mathrm{C}$, under vacuum better than $10^{-2} \mathrm{~Pa}$. Pore volumes were calculated using the $\alpha_{\mathrm{s}}$ method taking as reference the data obtained in a non porous silica [25], and mesopore size distributions were evaluated using the Broekhoff-de Boer method, simplified version with the Frenkel-Halsey-Hill equation (BdB-FHH) [26].

The possible modifications in the acidity properties caused by the alkaline treatments were studied using pyridine adsorption followed by infrared spectroscopy (FTIR). The infrared spectra were recorded in a Nicolet 6700 FTIR spectrometer $\left(60\right.$ scans, resolution $\left.4 \mathrm{~cm}^{-1}\right)$. The zeolite samples were pressed into thin self-supported wafers of $6 \mathrm{~mm}$ diameter. Before the experiments the wafers were outgassed in situ in a IR cell at $450{ }^{\circ} \mathrm{C}$ for $2 \mathrm{~h}$. After evacuation, the wafers were cooled to room temperature, and the initial (base) spectrum was recorded. The wafers were then exposed to pyridine vapour $\left(2.6 \times 10^{2} \mathrm{~Pa}\right)$ for $20 \mathrm{~min}$ for saturation at ambient 
temperature. After $2 \mathrm{~h}$ evacuation under vacuum the spectra were recorded. The wafers were then heated for $1.5 \mathrm{~h}$ at $200{ }^{\circ} \mathrm{C}$ for the evacuation of the physisorbed pyridine and then the spectra of chemisorbed pyridine were recorded. The background spectrum, recorded under identical operating condition, without sample, was always performed before each spectrum and automatically subtracted. The band intensities were corrected from slight differences in sample weight and band areas were calculated by fitting the spectral profiles with a Gaussian function using Peak-Fit ${ }^{\circledR}$ software.

\subsection{Catalytic tests}

The catalytic behaviour of the prepared zeolites was studied through two catalytic model reactions: $m$-xylene transformation and toluene hydrogenation. $m$-Xylene transformation was used to evaluate the influence of alkaline desilication treatment on the acidity and the porosity of the zeolites. The reaction was performed at $350{ }^{\circ} \mathrm{C}$ under atmospheric pressure; the samples were pre-treated in situ at $500{ }^{\circ} \mathrm{C}$ (heating rate of $5{ }^{\circ} \mathrm{C} \mathrm{min}{ }^{-1}$ ) under a constant flow of dry $\mathrm{N}_{2}\left(36 \mathrm{dm}^{3} \mathrm{~h}^{-1} \mathrm{~g}^{-1}\right)$ for $10 \mathrm{~h}$. The experiments were performed for 60 min time on stream (t.o.s.) using a flow of $3 \mathrm{~cm}^{3} \mathrm{~h}^{-1}$ of $m$-xylene diluted in $\mathrm{N}_{2}$ (molar ratio $\mathrm{N}_{2} / m$-xylene $=12$ ). Toluene hydrogenation was used as a model reaction to characterize the metal sites dispersed in the zeolitic support at $110{ }^{\circ} \mathrm{C}$, using $\mathrm{H}_{2}$ /toluene molar ratio of 45 with toluene diluted in $n$ hexane (1:5 molar ratio) and a space velocity of $100 \mathrm{~h}^{-1}$, according to the experimental procedure reported by Chupin et al. [27]. Before the catalytic tests the metal dispersed on the samples was reduced in situ under $\mathrm{H}_{2}$ flow $\left(6 \mathrm{dm}^{3} \mathrm{~h}^{-1} \mathrm{~g}^{-1}\right)$ at $500{ }^{\circ} \mathrm{C}$ for $3 \mathrm{~h}$. In both model reactions sampling was carried out at very short time-on-stream using a multiple loop valve (12 position VALCO), in order to accurately estimate the initial activity of the catalysts. The reaction products and unconverted reactant were analysed in a gas chromatograph (PerkinElmer auto-system) equipped with a $50 \mathrm{~m}$ dimethysyloxane DB-1 column and a flame ionization detector (FID).

The catalytic behaviour of the bi-functional catalysts was evaluated in the hydroisomerization of $n$-hexane at $250^{\circ} \mathrm{C}$, with a molar ratio $\mathrm{H}_{2} / n-\mathrm{C}_{6}=9$ and changing the space 
velocity from 6.6 to $53.4 \mathrm{~h}^{-1}$. Before the catalytic tests the metal was reduced using the same conditions described above. The reaction products were analysed by gas chromatography (HP 6890) equipped with a FID detector and a capillary column CP-SQUALANE.

\section{Results and discussion}

\subsection{Physicochemical characterization}

The powder XRD patterns of the pristine and desilicated zeolites (Fig.1) show that the alkaline treatment brought about a gradual decrease in the intensity of all the peaks, suggesting a progressive loss of the crystallinity. This was further confirmed by quantifying the degree of crystallinity, $C_{\mathrm{XRD}}$, defined as the ratio between the areas of peaks in the range $10-20^{\circ} 2 \theta$ in the diffraction patterns of each sample referred to the protonic structure HMOR chosen as reference. The results obtained are presented in Table 1 and corroborate the progressive loss of crystallinity with the concentration of the alkaline base. Data shows that for sample M/1.0, the loss of crystallinity is about $75 \%$, thus this sample was not further considered for the preparation of the bi-functional catalysts, nor was extensively characterized as all the other modified zeolites.

Fig. 1

\section{Table 1}

The influence of $\mathrm{NaOH}$ concentration and other experimental parameters (such as temperature and treatment duration, or the use of microwave radiation) in MOR desilication treatments were already discussed in previous works $[8,11]$ and here it is only summarized for data interpretation. Although increasing the severity of the treatment caused large crystallinity losses under all operation conditions, base concentration seemed to have the most important effect [11], leading to more significant mass loss, that in the case of, for example, sample $\mathrm{M} / 0.5$ reached about $30 \%$. 
The ${ }^{29}$ Si MAS NMR spectra of HMOR and alkaline treated samples are presented in Fig. 2 (A). The resonances corresponding to $\mathrm{Si}(0 \mathrm{Al})$ and $\mathrm{Si}(1 \mathrm{Al})$ at, respectively, -112 and $-107 \mathrm{ppm}$ [25], were detected in all the spectra with the exception of sample M/1.0. Indeed, the spectrum of sample M/1.0 is characterized by a broad and asymmetric peak centered at $-107 \mathrm{ppm}$ with a tail extending down up to $-80 \mathrm{ppm}$. This result reveals the presence of amorphous silica and silica-alumina, which is in agreement with the large loss of crystallinity detected by XRD patterns for this material [11]. All the other spectra demonstrate the Si removal promoted by the alkaline treatment since the relative intensities of the peaks $\mathrm{Si}(0 \mathrm{Al})$ and $\mathrm{Si}(1 \mathrm{Al})$ show an increasing trend with the $\mathrm{NaOH}$ concentration, as $\mathrm{Si}(1 \mathrm{Al})$ peak becomes gradually more intense until it reaches a maximum value in the case of $\mathrm{M} / 0.5$.

The ${ }^{27}$ Al MAS NMR spectra presented in Fig.2 (B) show that the starting material already has some non-framework 6-coordinated aluminium (resonance at $0 \mathrm{ppm}$ ) [28]. The ratio of the intensity of this peak and that at $55 \mathrm{ppm}$, corresponding to framework aluminum atoms [28] increases from 3.8 to 4.6 when the starting structure was treated with the less concentrated $\mathrm{NaOH}$ solution (sample $\mathrm{M} / 0.1$ ), showing that the treatment lead to a slight decrease of the nonframework Al species. A much less pronounced increase of this ratio is observed in the case of sample M/0.2 (4.0), and no variation was detected in the case of sample $M / 0.5$. The spectrum of sample of sample $\mathrm{M} / 1.0$ is significantly different from those of the other samples, revealing the presence of large amounts of 6- and 5-coordinated aluminium species, as discussed elsewhere [11].

Fig.2

The $\mathrm{Si} / \mathrm{Al}$ ratio of the tetrahedral framework ( $\left.\mathrm{Si} / \mathrm{Al}_{\text {framework}}\right)$ was estimated according to the method described in ref. 28, using the integrated areas of tetrahedral and octahedral nonframework aluminium and the total $\mathrm{Si} / \mathrm{Al}$ ratio obtained by bulk chemical analysis. The results obtained are quoted in Table 1 and confirm the partial desilication of the mordenite framework upon the alkaline treatments. The more extensive Si removal was obtained for the sample soaked in $\mathrm{NaOH} 0.5 \mathrm{M}$; this was accompanied by a large loss of the zeolite crystallinity (Table 
1), whereas the textural features (micro-, mesoporosity) remained quite preserved, as it will be further discussed below. Due to the extensive loss of crystallinity observed on sample M/1.0, the $\mathrm{Si} / \mathrm{Al}_{\text {framework }}$ was not estimated since the ascription of $\mathrm{Al}$ species (framework and nonframework) cannot be accurately made.

The $\mathrm{N}_{2}$ adsorption-desorption isotherms displayed in Fig. 3(A) show the evolution of the porous features of the pristine material with the alkaline treatment. In the case of samples treated with alkaline solutions with concentration higher than $0.1 \mathrm{M}$, the isotherms shift from the type I of HMOR (characteristic of a microporous structure) towards type I+IV isotherms with a well pronounced hysteresis loop, indicating the development of mesoporosity during the alkaline treatment. The hysteresis loop seems also to point out the presence of occluded porosity due to extra-framework species deposition due to the progressive increase of the desilication treatments severity.

The textural parameters quoted in Table 2 show that the most important textural modification corresponds to the development of a mesoporous structure [11]. This effect was particularly remarkable for samples $\mathrm{M} / 0.2$ and $\mathrm{M} / 0.5$, for which the ratio between the micropore and mesopore volumes $\left(V_{\text {micro }} / V_{\text {meso }}\right)$ is close to or even higher than unity. Furthermore, the mesopore size distributions - Fig. 3 (B) - show that these modified samples present broad bimodal distributions with maxima centered at 5.4 (both samples) and at 9.5 and $18.0 \mathrm{~nm}$ for $\mathrm{M} / 0.2$ and $\mathrm{M} / 0.5$, respectively.

The analysis the isotherms using the $\alpha_{\mathrm{S}}$ method allowed the estimation of the volume corresponding to the ultramicropres ( $V_{\text {ultra }}$, i.e. pores with width $<0.7 \mathrm{~nm}$, or in other words, the volume the characteristic zeolite porosity, and the volume of larger micropores $\left(V_{\text {super }}\right)$. The values quoted in Table 2 show that, with the exception of sample M/0.5, the treatments had practically no effect on the microporosity of the samples. In fact, only a very slightly increase of the volume correspondent of the larger micropores is observed for samples $\mathrm{M} / 0.1$ and $\mathrm{M} / 0.2$ which curiously are the samples where a decrease of the amount of extra-framework aluminum species, relative to the parent structure, was observed in the ${ }^{27}$ Al MAS NMR . 


\section{Fig.3}

\section{Table 2}

\subsection{Acidity characterization}

The acidity of parent and modified samples was evaluated by infrared spectroscopy (FTIR) in the spectral region of $1400-1700 \mathrm{~cm}^{-1}$, corresponding to the pyridine ring vibrations as a consequence of the basic molecule adsorption on Brönsted and Lewis acid sites. All samples present the bands characteristic to pyridine adsorption on Brönsted acid sites, with the formation of pyridinium, $\mathrm{PyH}^{+}$, at around 1545 and of pyridine coordinated to Lewis acid sites, $\mathrm{PyL}$, at $1455 \mathrm{~cm}^{-1}$ (spectra not shown).

The relative acid site concentration for parent and treated samples, calculated from the integrated area of $\mathrm{PyH}^{+}$and $\mathrm{PyL}$ bands using the values of the molar extinction coefficients of the bands at 1545 and $1455 \mathrm{~cm}^{-1}\left(1.67\right.$ and $2.22 \mathrm{~cm} \mathrm{\mu mol}^{-1}$, respectively) determined by Emeis [29] are presented on Table 3. As can be observed, the concentration of Brönsted sites remains practically unchanged upon desilication with $\mathrm{NaOH} 0.1 \mathrm{M}$. For M/0.2 sample a small decrease in $\mathrm{PyH}^{+}$band is noticed. For M/0.5 sample, where severe desilicaton conditions were applied more than $70 \%$ of the acid sites were lost upon desilication. In the case of Lewis acid sites the concentration remains practically unchanged for all samples.

\section{Table 3}

$m$-Xylene transformation (isomerisation and/or disproportionation) was used as catalytic model reaction [30] to evaluate the effect of alkaline treatment on the intrinsic properties of the zeolite, by correlating the changes in the surface acidity and porosity with the catalytic activity and selectivity. Under the experimental conditions used, conversions ranged from about $80 \%$ (fresh catalysts) to around $50 \%$ (after 60 min time on stream) for the pristine and treated zeolites. In all the cases a pronounced deactivation was registered in the first 5 min of reaction, 
followed by a smoother deactivation pattern until 60 min time on stream (not shown). Table 3 shows the deactivation percentages and the selectivities to the main reaction products that are detected at around $60 \%$ conversion, that is, after the more significant deactivation occurs, in order to compare all catalysts at about the same state of activity. As can be observed, the ratio between para and ortho-xylene isomers (p/o-X) is close to the equilibrium value of 1.04 [31] for all the samples, which indicates that no shape selective effects are present upon desilication.

Regarding the reaction products, a decrease in the ratio between the sum of isomerization (para and ortho-xylene isomers) and disproportionation products (comprising toluene and trimethylbenzenes, along with traces of benzene and tetramethylbenzenes), (I/D), was attained for $\mathrm{M} / 0.1$ and $\mathrm{M} / 0.2$ samples. These results indicate that the formation of bulky bimolecular intermediates that originate disproportionation products is favored in the case of these two samples. In fact the formation of disproportionation products results in a joint combination of two factors: acidity, since the formation of these products runs through a bimolecular mechanism and space because its formation demands enough space to accommodate bulky intermediates. In the case of $\mathrm{M} / 0.1$ sample the preservation of the zeolite acidity and a slight increase of the volume correspondent to the larger micropores $\left(\mathrm{V}_{\text {super }}\right)$, detected by $\mathrm{N}_{2}$ adsorption, as a consequence of the removal of extra-framework species that were already present on the parent zeolite (see discussion of the ${ }^{27} \mathrm{Al}$ MAS-NMR results), increased the formation of disproportionation products. For $\mathrm{M} / 0.2$ the slight decrease in the acidity was somewhat compensated by the increase in mesoporosity, which led to a I/D ratio close to the one obtained for $\mathrm{M} / 0.1$ sample. As the desilication conditions become more aggressive (sample $\mathrm{M} / 0.5$ ) the $\mathrm{I} / \mathrm{D}$ ratio increases, likely due to a loss of acid sites as a consequence of the alkaline treatment.

\subsection{Characterization of the metal function}

The metal function of Pt loaded samples was characterized by TEM, $\mathrm{H}_{2}$ chemisorption and by the model reaction of toluene hydrogenation. As the method used for metal loading was 
the incipient wetness impregnation it is assumed that the desired amount of $\mathrm{Pt}(1 \% \mathrm{wt}$.) was effectively introduced on the acid support.

Fig. 4 shows TEM images for all Pt loaded zeolites; the image corresponding to PtHMOR shows opaque crystals with some large dark spots corresponding to Pt particles located at the external surface. Although the microporous inner structure of the zeolite crystals cannot be visualized with the TEM equipment used (only the external surface is observed), we cannot discard that smaller Pt particles might be dispersed inside HMOR microporous structure. For the desilicated samples the number of Pt particles seen by TEM increased with the severity of the alkaline treatment, being considerably higher than that observed for Pt/MOR and Pt-M/0.1. Since the amount of Pt introduced in all the samples is identical (1 wt.\%), it appears that for the zeolites showing high acidity (Pt/MOR and Pt-M/0.1), Pt particles are located mainly inside the inner porosity.

On the other hand, larger metallic particles were observed for both Pt-M/0.2 and Pt$\mathrm{M} / 0.5$; these would be associated to the intercrystalline mesoporosity of MOR crystals developed during the desilication, which correspond to the lighter zones observed in the images. The formation of large metallic particles is attributed to the loss of crystallinity and of acid sites upon the desilication (especially in the case of sample $\mathrm{M} / 0.5$ ) reducing the amount of $\mathrm{Pt}$ dispersed inside the zeolite pore structure and favoring the metal deposition at the external surface. The increase in the external surface area $\left(A_{\text {ext }}\right)$ promoted by the alkaline treatment (Table 2) also favors the formation of large particles in the sample Pt-M/0.5 and may justify their detection in the case of sample Pt-M/0.2.

Table 4 compiles the results obtained by $\mathrm{H}_{2}$ chemisorption on the metal dispersed on the zeolites. The metallic dispersion was evaluated assuming that one $\mathrm{H}$ atom was chemisorbed by one surface Pt atom. The results obtained for all but sample Pt-M/0.1reveal that the alkali concentration used in the desilication treatment affects the metallic dispersion, showing that in the case of sample Pt-M/0.5 dispersion value drop of $25 \%$ compared to Pt-HMOR. The dispersion value obtained for Pt-M/0.2 is rather high considering the number of large metal particles observed in the TEM images, compared to Pt-HMOR. This seems to indicate that the 
number of small Pt particles formed in the inner porosity largely compensates the increase of the number of larger particles formed in the intercrystalline mesoporosity. Considering the characteristics of sample Pt-M/0.1, the expected dispersion value of this sample should be the highest in this series. Indeed, the desilication treatment lead to an increase of acidity due to the removal of some extraframework Al species (see NMR results) and no mesoporosity development was observed (see Table 2).

The mean particle size, $d_{\mathrm{H} 2}$, was evaluated assuming that $d_{\mathrm{H} 2}=1.08 / D_{\mathrm{H} 2}[32]$. Despite the low dispersion values, the average metal particle sizes are rather homogenous for all the samples ranging from $2.3-4.0 \mathrm{~nm}$. These values are smaller than the particle size range estimated from the analysis of TEM images, $\triangle \mathrm{d}_{\text {TEM }}$. However, it should be recalled that TEM small metallic particles are mainly located inside the support matrix, and thus cannot be visualized by TEM.

As expected the Pt particle size determined by TEM is within the mesoporous range since we are only observing the particles located either in the external surface of the zeolites or in the mesoporosity created during the desilication treatment. It is also interesting to remark that no Pt clusters larger than $5 \mathrm{~nm}$ were detected for any of the prepared zeolites; this contrast with the data frequently reported for other mesoporous supports (i.e., mesoporous activated carbons) [33].

Fig. 4

The hydrogenation of toluene is an additional characterization tool of the metal dispersion on a catalyst, since the hydrogenating activity is insensitive to the support structure [34]. Under the chosen operational conditions toluene was totally selective to methylcyclohexane. All samples present a sharp decrease in catalytic activity in the first $2 \mathrm{~min}$ t.o.s. followed by a plateau for higher t.o.s. (not shown). The initial hydrogenating activities, taken at 1 min t.o.s are presented in Table 4.

\section{Table 4}


It can be observed that the desilicated zeolites showed increased hydrogenating activity compared to the parent catalyst, with the highest activities achieved for Pt-M/0.2 and Pt-M/0.5 samples. According to the results previously discussed, in the case of the pristine Pt-HMOR and mild desilicated Pt-M/0.1 it can be assumed that the majority of Pt particles are located inside the zeolite pore structure. So, the lower hydrogenation activity observed with these samples can be explained by diffusion constraints and some pore blocking that hinders the occurrence of the catalytic reaction. The mild alkaline treatment performed on Pt-M/0.1 slightly increases the hydrogenating activity due, most probably, to the removal of the extra-framework species detected by the ${ }^{27 \mathrm{Al}}$ MAS-NMR spectra that seems to promote a slight increase in the volume associated to the wider micropores $\left(V_{\text {super }}\right)$ (see Table 2). On the other hand, the significant increase of the initial activity observed for samples Pt-M/0.2 and Pt-M/0.5 results from the fact that, the in these samples the Pt is located mainly at the external surface and toluene molecules can access the metal sites with no constraints.

The fact that the catalytic behavior of sample Pt-M/0.1 is more close to that of sample PtHMOR corroborates the hypothesis previously presented for the Pt particles location in this catalyst. On the other hand, in the case of Pt-M/0.2 and Pt-M/0.5 the number of Pt particles that are located in the external surface of the zeolite pore structure considerably increase (the majority of the metal particles seem to be located at the corroded areas of the crystal external surface) what seem to be the key to enhance the hydrogenating reaction, leading to higher initial activity parameter.

\subsection{Hydroisomerization of $n$-hexane}

In $n$-hexane hydroisomerization, metal sites dehydrogenate $n$-hexane into $n$-hexene, which is then converted by the acid sites into monobranched methylpentenes, dibranched dimethylbutenes or light products, depending on the balance between acid and metallic sites. These branched alkene intermediates are then hydrogenated at the metallic sites, giving methylpentanes (MPs) and dimethylbutanes (DMBs). When small metal contents are present, dehydrogenation and hydrogenation reactions limit the bifunctional process; the 
isomerization activity is proportional to the metal surface area. For high metal contents the reactions that occur at the metal sites become faster than the isomerization of the olefins on the acid sites and then the isomerization activity is independent of the metal area [35]. As in the case of our samples the metal content for all catalysts is about $1 \%$ (wt.\%), it is expected that the transformations of the olefinic intermediates that occur at the acid sites are the limiting step of the reaction. However, attending the hydrogenating activities for toluene hydrogenation it must be considered that in the case of desilicated samples with more concentrated $\mathrm{NaOH}$ solution the metal function can limit the reaction mechanism.

In order to investigate the presence of deactivation phenomena, a preliminary set of experiences were performed during 90 min t.o.s., at constant contact time (data not shown). It was found that, under the experimental conditions used, only a slight deactivation took place, lower than $5 \%$ in all cases. For samples Pt-HMOR and Pt-M/0.1 the deactivation is almost negligible (about 2\%), while for Pt-M/0.2 and especially for Pt-M/0.5 the deactivation becomes more expressive reaching almost $5 \%$ for $\mathrm{Pt}-\mathrm{M} / 0.5$. This can be attributed to the location of $\mathrm{Pt}$ particles mainly at the outer surface of the crystals, which allows the occurrence of some deactivation of the acid active sites inside the pore structure.

Fig. 5 shows the evolution of $n$-hexane conversion as a function of contact time (1/WHSV) for all catalysts. For all experiments, the reactor effluent was collected after $20 \mathrm{~min}$ t.o.s. for each contact time. Table 5 presents the values of catalytic activity, calculated by taking the slope of conversions versus contact time in the range below $10 \%$ conversion.

Fig. 5

\section{Table 5}

As can be observed from Fig. 5, the conversion does not follow a monotonous pattern with the severity of the desilication treatment, indicating that the overall yield is controlled by more than one parameter. Indeed, the highest conversion value and catalytic activity were 
obtained for Pt-M/0.2 sample, showing a better performance than that of the pristine zeolite. This behavior has to be attributed to several factors, including the mesopore structure as well as a good preservation of the framework crystallinity and acidity. All these issues would allow an improved molecular diffusion of the compounds, resulting in an increased conversion. For both $\mathrm{Pt}-\mathrm{M} / 0.1$ and Pt-M/0.5, conversions were smaller in all contact time range. In the case of Pt$\mathrm{M} / 0.1$ sample, the mild conditions used during the alkaline treatment are not enough to develop mesoporosity; just a very small increase in volume of the wider micropores, most probably resulting from the removal of some extra-framework species present in the parent samples (Table 2 and Fig.2), which was not enough to improve the catalytic conversion. On the other hand, for Pt-M/0.5, its low catalytic performance must be related to the lower crystallinity presented by the sample, in addition to a significant loss of acid sites as a consequence of severe alkaline treatment, which is in line with pyridine adsorption and $m$-xylene isosomerization results (Table 3). The occurrence of some deactivation during the catalytic test must also be considered.

Regarding the product distribution, mainly isomerization products were detected: monobranched methylpentanes (2-MP and 3-MP) and dibranched dimethylbutanes (2,2-DMB and 2,3-DMB). Some trace amounts of benzene (B), methylcyclopentane (MCP) and cracking products $\left(\mathrm{C}_{1}-\mathrm{C}_{5}\right)$ were also detected. Table 5 shows the product distribution (selectivities in molar percentages) at similar conversion, around $10 \%$. For all the studied catalysts the major reaction products are the monobranched isomers, with a 2-MP/3-MP ratio close to the equilibrium value (1.6) [36].

Fig. 6 shows the relative amounts of mono and dibranched isomers (most valuable ones due to its higher octane number) using the ratio between methylpentanes and dimethylbutanes (MP/DMB) and the ratio between the two dibranched isomers (2,3-DMB/2,2-DMB).

Fig. 6

The sample prepared upon mild alkaline treatment (Pt-M/0.1) presents the highest selectivity towards dibranched isomers, as observed for the low MP/DMB ratio. In contrasts, 
increasing the alkaline concentration affected the selectivity, although a better performance was obtained for Pt-M/0.5 (behaves rather close to the pristine zeolite) compared to Pt-M/0.2. This contrasts with the high activity of the latter, as evidence in Table 5. Regarding the dibranched isomers distribution, both Pt-M/0.1 and Pt-M/0.5 samples showed enhanced selectivity into 2,2DMB, which involves a secondary carbenium ion, through either isomerization of methylpentanes (MP) or a methyl shift of 2,3-DMB. [37].

Since there is no available data in the literature on $n$-hexane hydroisomerization over desilicated Pt-MOR catalysts, we have carried out a comparison with other zeolitic structures such as MFI and BEA [20-23]. For instance Song et al. [21] studied the isomerization of alkali treated Pt-ZSM-5 and concluded that the distribution of isomers, namely DMBs, depends on the strong acid sites of the catalysts along with the formation of mesopores during alkaline desilication. On the other hand, Chao et al. [20] observed an extra high 2,2-DMB sorption capacity in hierarchical MFI. Since 2,2-DMB molecule is bulkier than 2,3-DMB this effect was attributed to the porosity modifications that resulted from the desilication treatments, which is in accordance with the results presented by $\mathrm{Pt}-\mathrm{M} / 0.1$ and $\mathrm{Pt}-\mathrm{M} / 0.5$ samples. It is interesting to point out that these samples displayed rather similar catalytic behavior, despite their different physicochemical features, including porosity, crystallinity, surface acidity and metal dispersion/location.

For Pt-M/0.1 the preferential formation of 2,2-DMB was obtained mainly through the secondary transformation of methylpentanes (see Table 5), which can be attributed to the slight modification performed on the microporosity, along with the maintenance of the acidity characteristic of the pristine zeolite structure, which is also corroborated by the results obtained in $m$-xylene transformation, where an increased selectivity in bimolecular products resulting from disproportionation reaction was achieved. For Pt-M/0.5 the higher selectivity towards 2,2DMB is obtained not only from methylpentanes transformation but also from 2,3-DMB methyl shift as a consequence of the mesoporosity developed during the alkaline digestion and confirmed by TEM images and gas adsorption data. Additionally, as for this catalyst the Pt particles are located mainly at the outer surface, with low platinum loading inside the pores, it 
should not be disregarded the possible formation of 2,2-DMB by direct transformation of $n$ hexane $[37,38]$.

Comparatively, the MP/DMB ratio is lower in Pt-M/0.5 than in Pt-M/0.1, which could be explained in terms of the lost of acid sites as a consequence of the alkaline treatment, which is in accordance with the higher silica removal (Table 1) achieved after treatment in $0.5 \mathrm{M}$ $\mathrm{NaOH}$.

In what concerns to the presence of light products $\left(\mathrm{C}_{1}-\mathrm{C}_{5}\right)$ these are detected in higher amounts in Pt-M/0.1 and Pt-M/0.5 samples. In the case of $0.1 \mathrm{M}$ treated sample the origin of these products can be explained attending to the slightly larger channels that promotes the occurrence of rapid bimolecular transformations between the formed isomers and some primary cracking products, leading to a broad product distribution [35]. In the case of Pt-M/0.5 sample, the presence of large metal particles, visualized in TEM images, leads to the occurrence of hydrogenolysis reactions leading to the presence of significant amount of $\mathrm{C}_{1}-\mathrm{C}_{2}$ fragments.

\section{Conclusions}

Bifunctional Pt-HMOR catalysts based on desilicated mordenite zeolite were prepared, characterized and tested in the catalytic reaction of $n$-hexane hydroisomerization. The concentration of $\mathrm{NaOH}$ used in the desilication treatments showed a marked effect on both the structural parameters of the catalysts and their catalytic activity. For low $\mathrm{NaOH}$ concentration (ca. $0.1 \mathrm{M}$ ) no gain in mesoporosity was observed, but rather a slight increase in the volume corrresponding to micropore larger than $0.7 \mathrm{~nm}$ (supermicropores) indicating a washing effect, from extraframework material deposited probably at the pore mouths of the parent zeolite, which complemented by the preservation of the zeolite acidity was enough to improve selectivity towards disproportionation products in $m$-xylene transformation. When more concentrated $\mathrm{NaOH}$ solutions are used a clear development of mesoporosity is achieved with the severity of the alkaline treatment. This is accompanied by a strong fall in crystallinity along with some loss of acid sites, evidenced by a decrease in the occurrence of bimolecular reactions 
during $m$-xylene transformation along with a lower concentration of acid sites showed by pyridine adsorption.

The Pt dispersion/location is also influenced by the modifications on the texture and acidity imposed by the alkaline treatments. Similar TEM patterns and low hydrogenating activities were obtained for the pristine and low desilicated samples, denoting an identical dispersion/location of the metal particles which would be mainly located at the inner pores of the zeolite. On the other hand, large metal particles can be observed for Pt-M/0.2 and, especially for Pt-M/0.5 along with a higher hydrogenating activity, which can be explained by a fast access of the reactant molecules to the large metal particles exposed at the intercrystalline mesopores of desilicated samples.

The potential application of Pt loaded catalysts based on desilicated MOR zeolite was evaluated using $n$-hexane hydroisomerization reaction where the most desired products are the dibranched dimethylbutanes (DMBs). The higher selectivity for dibranched over monobranched isomers was obtained in Pt-M/0.1 sample. This behavior can be attributed to an easier formation of the dibranched isomers due to the slight enlargement of the micropores along with the good preservation of the zeolite acidity

This work is a new example in which the mesoporosity development through severe desilication is not able to improve the catalytic efficiency. On the other hand, mild alkaline treatments slightly enlarge the micropores, and preserves the acidity of the zeolite structure leading to an increase selectivity of dibranched over monobranched isomers, suggesting that customized mild alkaline desilication treatments could be used to produce optimal catalysts with enhanced performance.

\section{Aknowledgments}

This work was financially supported by FCT (Portugal) through strategic projects PEstOE/QUI/UI0612/2013 (CQB), and PEst-C/CTM/LA0011/2013, Portuguese NMR Network 


\section{References}

[1] R.H. Jensen in: M. Guisnet, J.P. Gilson (eds) Zeolites for cleaner technologies, vol 3. Imperial College Press, London (2002), p. 73-105.

[2] J.F. Allain, P. Magnoux, Ph. Schulz, M. Guisnet, Appl. Catal. A: Gen., 152 (1997) 221-235.

[3] E. Blomsma, J.A. Martens, P.A. Jacobs, J. Catal. 159 (1996) 323 -331.

[4] F. Alvarez, F.R. Ribeiro, G. Perot, C. Thomazeau, M. Guisnet, J. Catal. 162 (1996) 179-189.

[5] R. Roldán, F. J. Romero, C. Jiménez-Sanchidrián, J. M. Marinas, J.P. Goméz, Appl. Catal. A: Gen., 288 (2005) 104-115.

[6] M. Guisnet, G. Perot, in: A.E. Rodrigues, L.D. Rollmann, C. Naccache (eds), Zeolites, Science and Technology, NATO ASI series, The Hague, (1984), p. 397-420.

[7] J.-K. Lee, H.-K Rhee, Catal. Today 38 (1997) 235-242.

[8] V. Paixão, R. Monteiro, M. Andrade, A. Fernandes, J. Rocha, A. P. Carvalho, A. Martins, Appl. Catal. A: Gen. 402 (2011) 59-68.

[9] D. A. Young, US Patent 3326797.

[10] M. Sugimoto, H. Katsuna, T. Murakawa, Appl. Catal. A: Gen. 96 (1993) 201-206.

[11] V. Paixão, A. P. Carvalho, J. Rocha, A. Fernandes, A. Martins, Microporous Mesoporous Mat. 131 (2010) 350-357.

[12] A.N.C. van Laak, S.L. Sagala, J. Zecevic, H. Friederich, P.E. de Jongh, K.P. de Jong, J. Catal., 276 (2010) 170-180.

[13] J. Pérez-Ramírez, C. H. Christensen, K. Egeblad, C.H. Christensen, J.C. Groen, Chem Soc. Rev. 37 (2008) 2530-2542.

[14] V. Machado, J. Rocha, A.P. Carvalho, A. Martins, Appl. Catal. A: Gen. 445-446 (2012) 329-338.

[15] J. Pérez-Ramírez, S. Abelló, A. Bonilla, J. C. Groen, Adv. Funct. Mater., 19 (2009) 164172.

[16] S. van Donk, A. H. Janssen, J. H. Bitter, K. P. de Jong, Catal. Reviews, 45 (2003) $297-$ 319. 
[17]Y. N. Li, S.L. Liu, Z.K. Zhang, S.J. Xie, X.X. Zhu, L.Y. Xu, Appl. Catal. A: Gen. 338 (2008) 100-113.

[18]D. Verboekend, G. Vilé, J. Pérez-Ramírez, Adv. Funct. Mater. 22 (2012) 916-928.

[19] J.C. Groen, J. Pérez-Ramírez in: A. Cybulski, J.A. Moulijn, J.A. Stankiewicz (eds), Novel concepts in catalysis and chemical reactors, Wiley-VCH, Wenheim, (2010) p.31.

[20] P.-H. Chao, S.-T. Tsai, S.L. Chang, I. Wang, T.-C. Tsai, Top. Catal. 53 (2010) 231-237.

[21] Y.-Q. Song, Y.-L. Feng, F. Liu, C.-L. Kang, X.-L Zhou, J. Mol. Catal. A: Chem. 310 (2009) 130-137.

[22] B. K. Modhera, M. Chakraborty, H. C. Bajaj, P. A. Parikh, Catal. Lett. 141 (2011) 11821190.

[23] J. Groen, L.A.A. Peffr, J. Pérez-Ramírez, Micropor. Mesopor. Mater., 69 (2004) 29-34.

[24] C. Pedrero, T. Waku, E. Iglesia, J. Catal. 233 (2004) 242-255.

[25] S.J. Greeg, K.S. W. Sing, Adsorption, Surface Area and Porosity, $2^{\text {nd }}$ Edition, Academic Press, London, 1982.

[26] W.W. Lukens Jr, P. Schmidt-Winkel, D. Zhao, J. Feng, G.D. Stucky, Langmuir, 15 (1999) 5403-5409.

[27] J. Chupin, N.S. Gnep, S. Lacombe, M. Guisnet, Appl. Catal. A: Gen. 206 (2001) 43-56.

[28]G. Engelhardt, D. Michel, High-Resolution Solid-State NMR of Silicates and Zeolites, John Wiley \& Sons, New York, 1987.

[29] C.A. Emeis, J. Catal., 141(1993) 347-354.

[30] J. Čejka, B. Wichtlerlová, Catal. Rev. 44(3) (2002) 375-421.

[31] W.J. Taylor, D.D. Wagman, M.G. Williams, K.S. Pitzer, F.D. Rossini, J. Res. Nat. Bur. Stand., 37 (1946) 95-122.

[32] J.L. Figueiredo, F. Ramôa Ribeiro, Catálise Heterogénea, $2^{\text {nd }}$ Edition, Fundação Calouste Gulbenkian, Lisboa, 2007.

[33] S. Fernandes, M. Andrade, C. O. Ania, A. Martins, J. Pires, A. P. Carvalho, Microporous Mesoporous Mater. 163 (2012) 21-28.

[34] M. Boudart, J. Mol. Catal. 30 (1985) 27-38. 
[35] F. Ribeiro, C. Marcilly, M. Guisnet, J. Catal. 78 (1982) 267-274.

[36] J.-K. Chen, A.M. Martin, Y.G. Kim, V.T. John, Ind. Eng. Chem. Res. 27 (1998) 401-409.

[37] A. van de Runstraat, J.A. Kamp., P.J. Stobbeblaar, J. van Grondelle, S. Krijnen, R.A. van Santen, J. Catal. 171 (1997) 77-84.

[38] J.F. Allain, P. Magnoux, Ph. Schulz, M. Guisnet, in Proceedings of the DGMK-

Conference: Catalysis on solid acid and bases”, J. Weitkamp, J. Lücke Ed.,German Society for Petroleum and Coal Science and Technology, 1996, pag. 219. 
Figure captions

Figure 1. X-ray diffraction patterns of HMOR and indicated alkaline treated samples.

Figure 2. ${ }^{29} \mathrm{Si}$ (A) and ${ }^{27} \mathrm{Al}$ (B) MAS-NMR spectra of (a) HMOR (b) M/0.1; (c) M/0.2; (d) $\mathrm{M} / 0.5$; and (e) $\mathrm{M} / 1.0$.

Figure 3. (A) Nitrogen adsorption-desorption isotherms at $-196{ }^{\circ} \mathrm{C}$ on $\mathrm{HMOR}$ and on alkaline treated samples (closed symbols are desorption points) and (B) correspondent mesoporous size distribution. $\diamond$-HMOR; $\bigcirc-\mathrm{M} / 0.1 ; \triangle-\mathrm{M} / 0.2 ; \square-\mathrm{M} / 0.5$.

Figure 4. TEM micrographs of parent and desilicated samples.

Figure 5. Conversion as a function of contact time (1/WHSV) for $n$-hexane hydroisomerization at $250^{\circ} \mathrm{C}$.

Figure 6. Ratio between the sum of monobranched (MP) and dibranched (DMB) isomers and ratio between dibranched 2,3-DMB and 2,2-DMB for $n$-hexane hydroisomerization at similar conversion $(\approx 10 \%)$.

Table 1. Degree of crystallinity, $C_{\mathrm{XRD}}, \mathrm{Si} / \mathrm{Al}$ ratios obtained from bulk chemical analysis (total) and from NMR spectroscopy results (framework).

\begin{tabular}{llll}
\hline Sample & $C_{\text {XRD }}(\%)$ & $\mathrm{Si} / \mathrm{Al}_{\text {total }}$ & $\mathrm{Si} / \mathrm{Al}_{\text {framework }}$ \\
\hline HMOR & 100 & 9.5 & 11.1 \\
\hdashline $\mathrm{M} / 0.1$ & 86 & 10.5 & 11.5 \\
$\mathrm{M} / 0.2$ & 83 & 8.6 & 10.6 \\
$\mathrm{M} / 0.5$ & 74 & 5.1 & 5.9 \\
$\mathrm{M} / 1.0$ & 24 & 6.5 & n.d. $^{*}$ \\
\hline
\end{tabular}

* This value was not determined due to the great loss of crystalinity of the sample (see text). 
Table 2. Microporous volume ( $\left.V_{\text {micro }}\right)$, ultra and supermicroporous volume ( $V_{\text {ultra }}$ and $V_{\text {super }}$ ), mesoporous and total porous volumes ( $V_{\text {meso }}$ and $\left.V_{\text {total }}\right)$ and external area $\left(A_{\text {ext }}\right)$ of the samples.

\begin{tabular}{lllllll}
\hline Sample & $\begin{array}{l}V_{\text {micro }}{ }^{\mathrm{a}} \\
\left(\mathrm{cm}^{3} \mathrm{~g}^{-1}\right)\end{array}$ & $\begin{array}{l}V_{\text {ultra }}{ }^{\mathrm{a}} \\
\left(\mathrm{cm}^{3} \mathrm{~g}^{-1}\right)\end{array}$ & $\begin{array}{l}V_{\text {super }}{ }^{\mathrm{a}} \\
\left(\mathrm{cm}^{3} \mathrm{~g}^{-1}\right)\end{array}$ & $\begin{array}{l}V_{\text {total }}{ }^{\mathrm{b}} \\
\left(\mathrm{cm}^{3} \mathrm{~g}^{-1}\right)\end{array}$ & $\begin{array}{l}V_{\text {meso }}{ }^{\mathrm{c}} \\
\left(\mathrm{cm}^{3} \mathrm{~g}^{-1}\right)\end{array}$ & $\begin{array}{l}A_{\text {ext }} \\
\left(\mathrm{m}^{2} \mathrm{~g}^{-1}\right)\end{array}$ \\
\hline $\mathrm{HMOR}$ & 0.20 & 0.19 & 0.01 & 0.25 & 0.05 & 24 \\
\hdashline $\mathrm{M} / 0.1$ & 0.20 & 0.18 & 0.02 & 0.24 & 0.04 & 25 \\
$\mathrm{M} / 0.2$ & 0.21 & 0.19 & 0.02 & 0.40 & 0.19 & 133 \\
$\mathrm{M} / 0.5$ & 0.17 & 0.16 & 0.01 & 0.38 & 0.21 & 125 \\
\hline
\end{tabular}

${ }^{a}$ estimated from $\alpha_{S}$ method

${ }^{\mathrm{b}} V_{\text {total }}$ - volume adsorbed at $p / p^{0}=0.95$

${ }^{\mathrm{c}} V_{\text {meso }}=V_{\text {total }}-V_{\text {micro }}$

Table 3. m-Xylene transformation reaction (isomerisation and/or disproportionation): Conversion, $\Delta$ Conv, para /ortho-Xylene $(p / o-X)$ and isomerisation/disproportionation $(I / D)$ ratio. Acid sites concentration estimated from pyridine adsorption followed by IR after evacuation at $200^{\circ} \mathrm{C}$.

\begin{tabular}{|c|c|c|c|c|c|c|}
\hline \multirow{2}{*}{ Sample } & \multicolumn{4}{|c|}{$m$-xylene transformation } & \multicolumn{2}{|c|}{$\begin{array}{l}\text { Pyridine } \\
\text { adsorption }\end{array}$} \\
\hline & Conv. & $\Delta$ Conc. $^{\mathrm{a}}$ & $\mathrm{p} / \mathrm{o}-\mathrm{X}^{\mathrm{b}}$ & $\mathrm{I} / \mathrm{D}^{\mathrm{c}}$ & $\begin{array}{c}\mathrm{PyH}^{+} \\
\mathrm{mmol} \mathrm{g}^{-1}\end{array}$ & $\begin{array}{c}\text { PyL } \\
\mathrm{mmol} \mathrm{g}^{-1}\end{array}$ \\
\hline HMOR & 62.9 & 30 & 1.3 & 0.7 & 0.71 & 0.14 \\
\hline $\mathrm{M} / 0.1$ & 62.3 & 34 & 1.4 & 0.4 & 0.69 & 0.14 \\
\hline $\mathrm{M} / 0.2$ & 61.6 & 22 & 1.4 & 0.5 & 0.61 & 0.15 \\
\hline $\mathrm{M} / 0.5$ & 62.3 & 25 & 1.4 & 0.7 & 0.18 & 0.15 \\
\hline
\end{tabular}

a difference between initial and final conversions taken at $0.5 \mathrm{~min}$ and $60 \mathrm{~min}$ t.o.s, respectively

${ }^{\mathrm{b}}$ ratio between para and ortho-xylene isomers

${ }^{c}$ ratio between the sum of isomerisation and disproportionation products.

Table 4. Metal dispersion, $\mathrm{D}_{\mathrm{H} 2}$, and mean particle size, $\mathrm{d}_{\mathrm{H} 2}$, from $\mathrm{H}_{2}$ chemisorption, particle size range, $\Delta \mathrm{d}_{\mathrm{TEM}}$, estimated from TEM images, and initial hydrogenating activities for toluene hydrogenation reaction. 


\begin{tabular}{ccccc}
\hline Sample & $\begin{array}{c}\mathrm{D}_{\mathrm{H} 2} \\
(\%)\end{array}$ & $\begin{array}{c}\mathrm{d}_{\mathrm{H} 2} \\
(\mathrm{~nm})\end{array}$ & $\begin{array}{c}\Delta \mathrm{d}_{\mathrm{TEM}} \\
(\mathrm{nm})\end{array}$ & $\begin{array}{c}\text { Initial activity } \\
\left(\mathrm{mol} \mathrm{h}^{-1} \mathrm{~g}^{-1} \mathrm{Pt}\right)\end{array}$ \\
\hline Pt-HMOR & 37.0 & 2.9 & $3-15$ & 0.70 \\
\hline $\mathrm{Pt}-\mathrm{M} / 0.1$ & n.d & n.d. & $2-15$ & 0.86 \\
$\mathrm{Pt}-\mathrm{M} / 0.2$ & 47.6 & 2.3 & $3-15$ & 2.44 \\
$\mathrm{Pt}-\mathrm{M} / 0.5$ & 27.1 & 4.0 & $5-20$ & 3.41 \\
\hline
\end{tabular}

Table 5. Catalytic activity and product selectivities for $n$-hexane hydroisomerization at $250{ }^{\circ} \mathrm{C}$, at similar conversion (around 10\%).

\begin{tabular}{ccccccccc}
\hline Sample & $\begin{array}{l}\text { Activity } \\
\text { mol h}^{-1} \mathrm{~g}^{-1}\end{array}$ & \multicolumn{7}{c}{ Selectivities (\%) } \\
\cline { 3 - 9 } & & $\mathrm{C}_{1}-\mathrm{C}_{5}$ & 2,2-DMB & 2,3-DMB & 2-MP & 3-MP & MCP & B \\
\hline Pt-HMOR & 2.4 & 4.9 & 4.5 & 11.3 & 46.1 & 28.6 & 3.2 & 1.4 \\
\hdashline Pt-M/0.1 & 1.1 & 14.4 & 7.7 & 10.0 & 37.9 & 22.5 & 2.1 & 5.4 \\
Pt-M/0.2 & 2.8 & 1.5 & 2.2 & 9.6 & 49.9 & 32.9 & 3.2 & 0.7 \\
Pt-M/0.5 & 0.7 & 8.6 & 6.2 & 8.5 & 41.2 & 27.9 & 6.5 & 1.0 \\
\hline
\end{tabular}


Figure 1

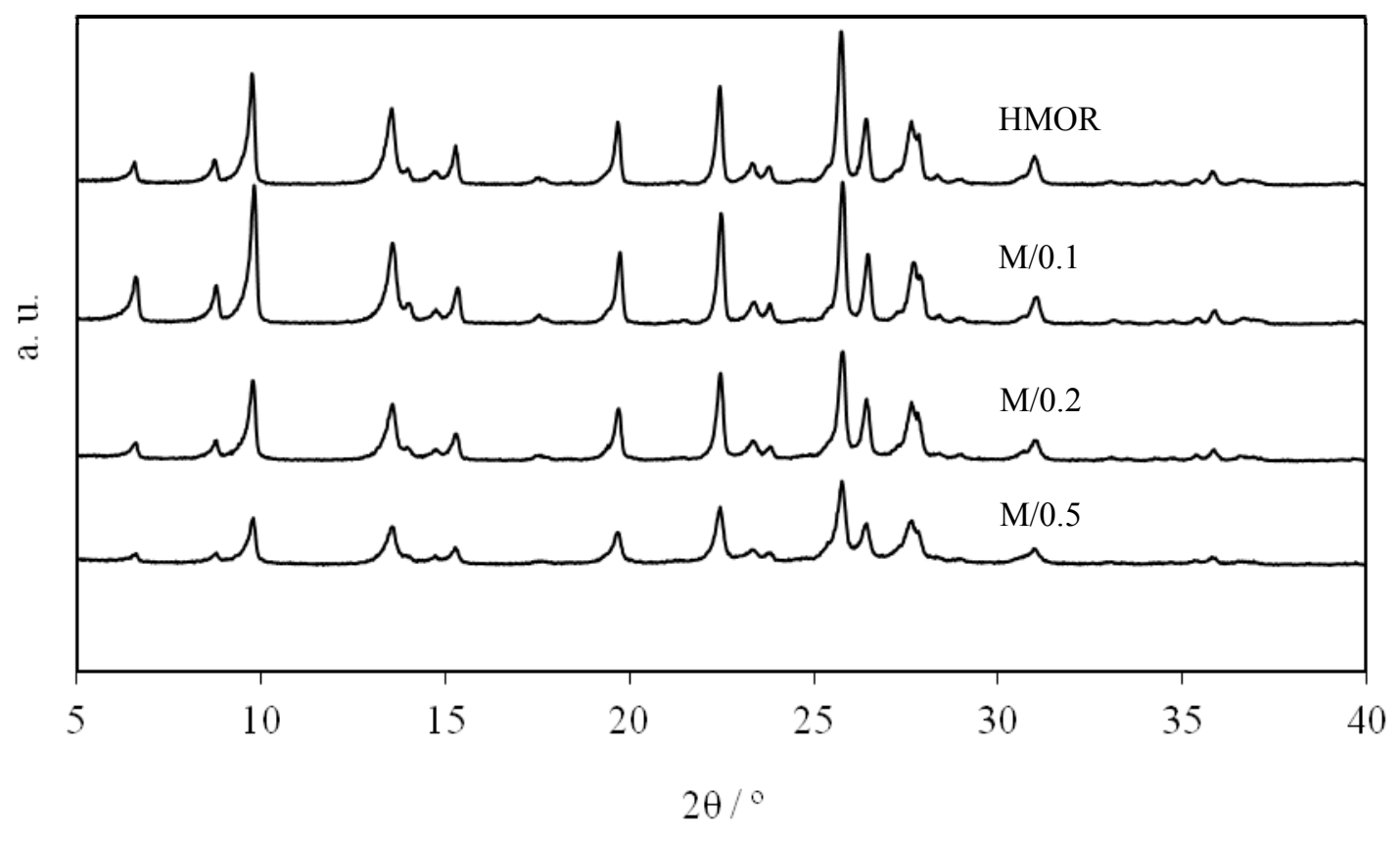


Figure 2

(A)

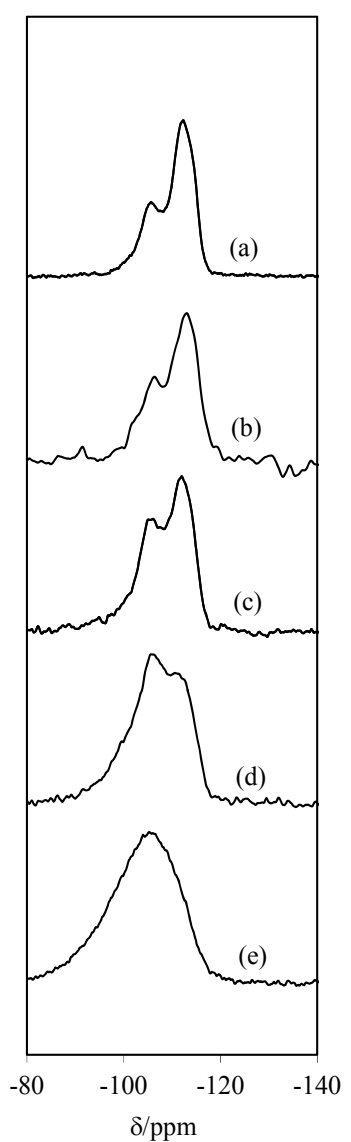

(B)

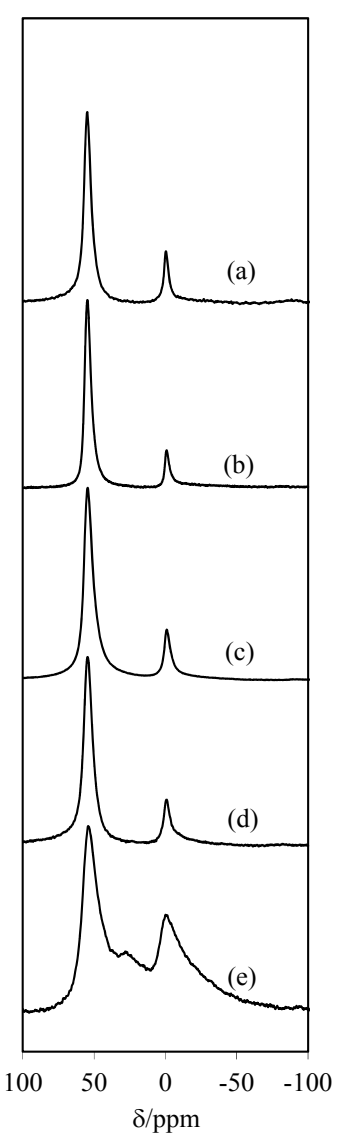


Figure 3

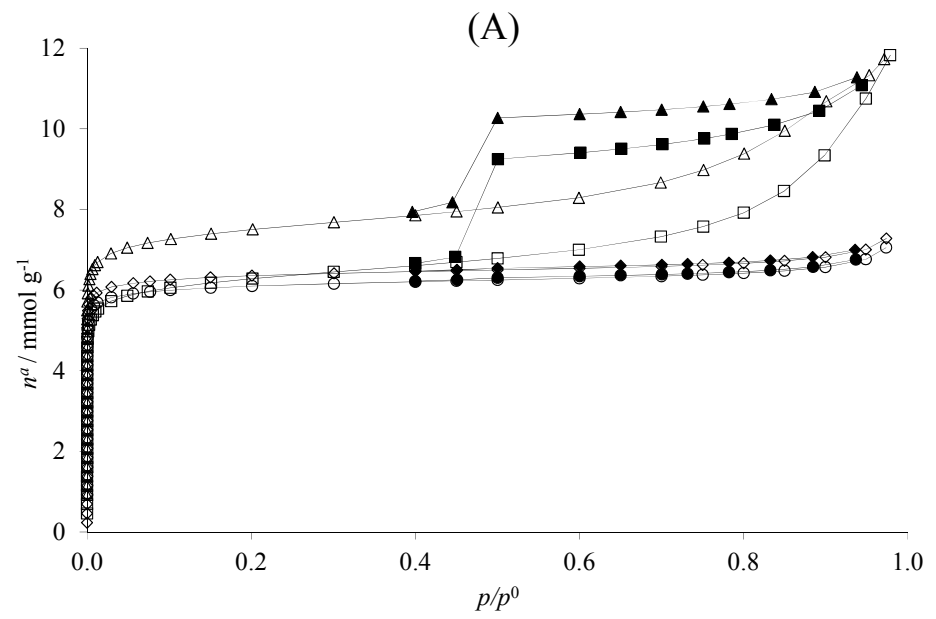

(B)

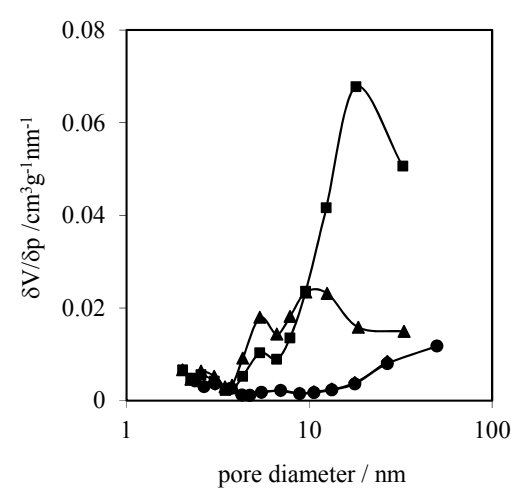


Figure 4
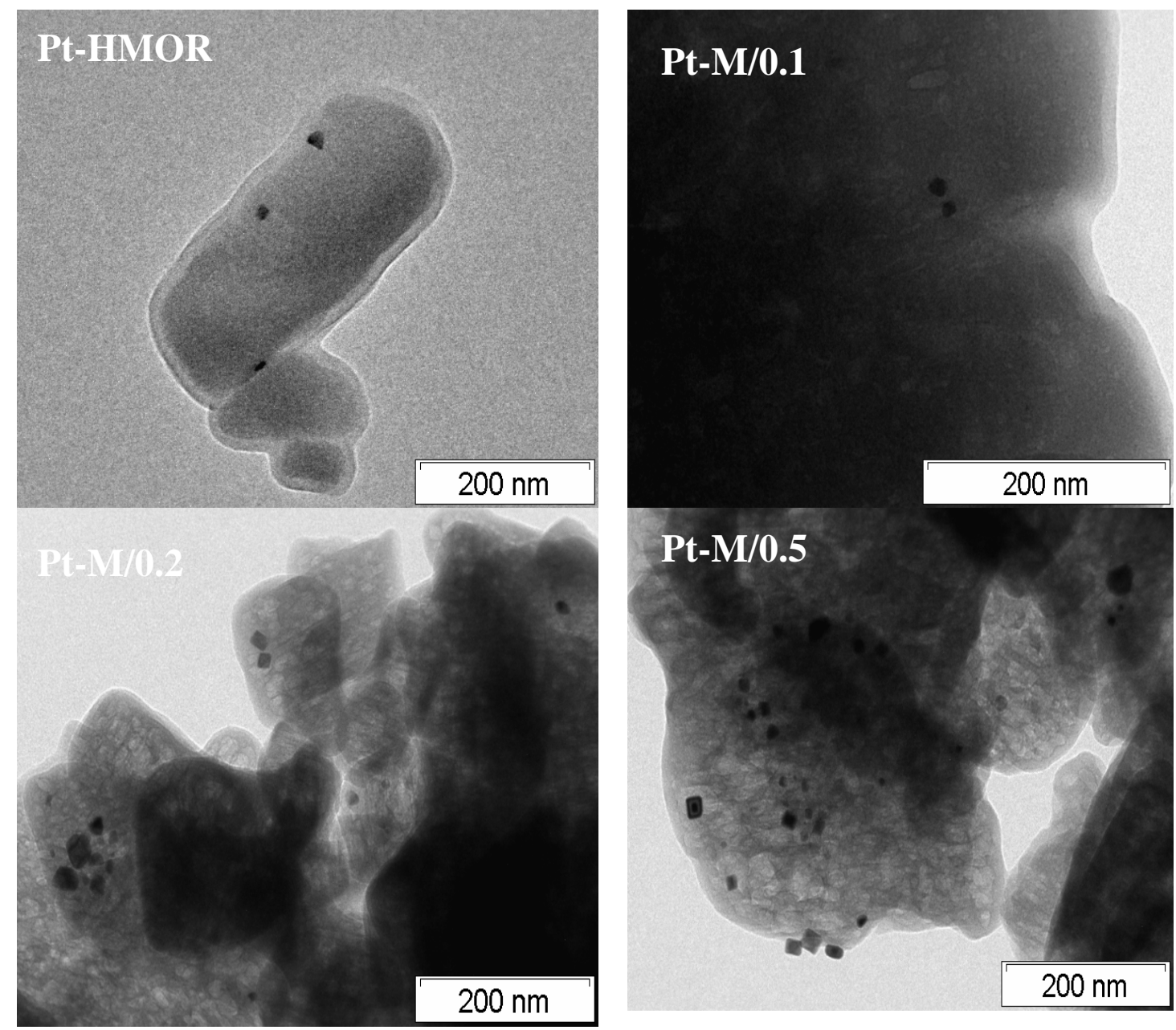
Figure 5

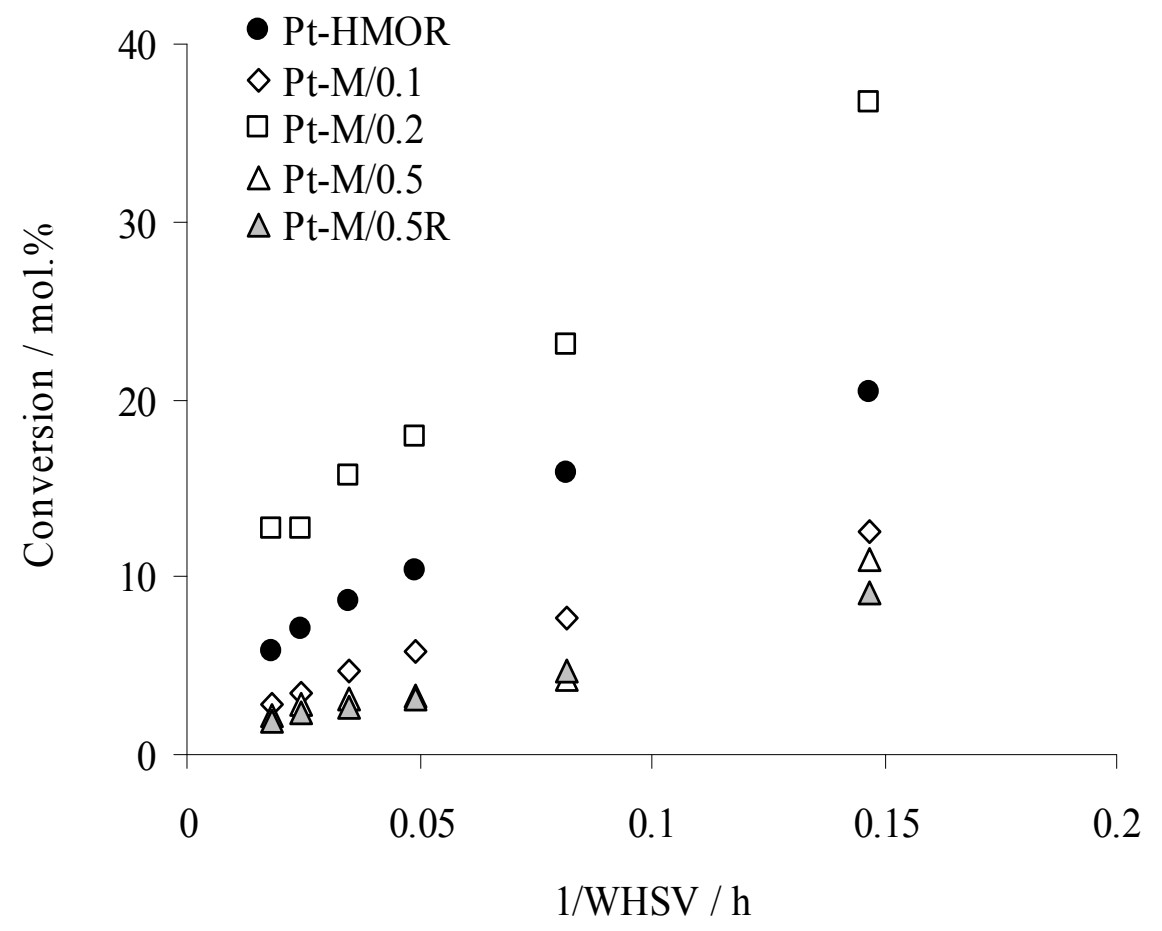


Figure 6

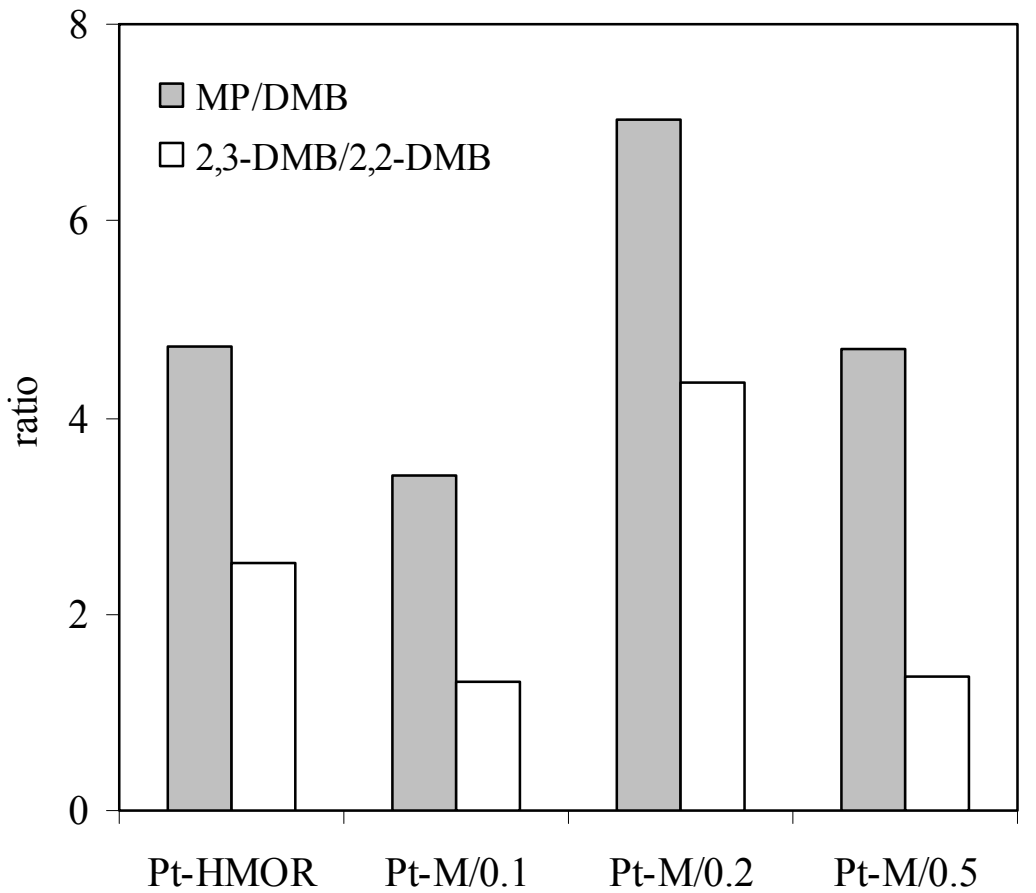

